Discussion Paper No. 08-073

The Intergenerational Transmission of Health in Early Childhood

Katja Coneus and C. Katharina Spiess

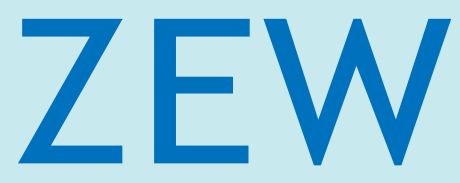

Zentrum für Europäische Wirtschaftsforschung $\mathrm{GmbH}$

Centre for European

Economic Research 
Discussion Paper No. 08-073

\title{
The Intergenerational Transmission of Health in Early Childhood
}

\author{
Katja Coneus and C. Katharina Spiess
}

Download this ZEW Discussion Paper from our ftp server:

ftp://ftp.zew.de/pub/zew-docs/dp/dp08073.pdf

Die Discussion Papers dienen einer möglichst schnellen Verbreitung von neueren Forschungsarbeiten des ZEW. Die Beiträge liegen in alleiniger Verantwortung der Autoren und stellen nicht notwendigerweise die Meinung des ZEW dar.

Discussion Papers are intended to make results of ZEW research promptly available to other economists in order to encourage discussion and suggestions for revisions. The authors are solely responsible for the contents which do not necessarily represent the opinion of the ZEW. 


\section{Summary}

The health of children has been increasingly becoming the subject of economic research during the last few years. So far, most of the studies have focused on both the links between a child's socio-economic background and its state of health and on the long-term effects of a poor health during childhood.

Only few studies have examined whether links between the health of children and the health of their parents can be determined on the basis of micro level data. The following study focuses on precisely this issue. It analyzes links between the health of children during their first three years and the health of their mothers and fathers. Moreover, the intergenerational transmission of health risks (from parents to children) will be analyzed.

On the basis of the German Socio-Economic Panel (SOEP), a database which is representative for Germany, three different groups of health measures can be distinguished: 1) anthropometric measures, 2) self-assessment of health, 3) “objective” health measures, such as the number of doctor or hospital visits. These measures are repeatedly observed for both the children and the parents. Besides that, the study employs smoking as a variable of parental health behaviour.

The results of this study show that there is a significant relation between infant and parental health. However, this relation is less marked when it comes to the anthropometric measures of both generations. Moreover, the results indicate that the intergenerational transmission of health risks is largest for those health measures which are based on maternal assessments.

Thus, our analyses contribute to those underlining the importance of maternal well-being for the health of children. That means that infant health can be promoted by strengthening the physical and mental health of mothers. 


\section{Das wichtigste in Kürze}

Die Analyse des Gesundheitszustandes von Kindern ist in den letzten Jahren vermehrt in den Vordergrund ökonomischer Analysen gerückt. Dabei haben sich bisherige Arbeiten vorrangig mit dem Zusammenhang zwischen dem sozioökonomischen Hintergrund von Kindern und deren Gesundheit sowie den langfristigen Folgen eines schlechten Gesundheitszustandes im Kindesalter beschäftigt.

Nur wenige Analysen untersuchen inwiefern, auf der Basis von Mikrodaten ein Zusammenhang zwischen der Gesundheit von Kindern und ihren Eltern festzumachen ist. Die vorliegende Untersuchung hat dies zum Gegenstand: Sie analysiert den Zusammenhang zwischen der Gesundheit von Kindern in den ersten drei Lebensjahren und dem Gesundheitszustand von Müttern und Vätern. Darüber hinaus wird die Weitergabe (,intergenerationale Transmission“) der elterlichen Gesundheit auf die ihrer Kinder analysiert.

Basierend auf einer für Deutschland repräsentativen Datenbasis, dem Sozio-oekonomischen Panel (SOEP) für die Jahre 2002-2006, können drei unterschiedliche Gruppen von Gesundheitsmaßen unterschieden werden: (1) anthropometrische Maße, (2) Gesundheitseinschätzungen der Eltern und (3) „objektive“ Gesundheitsmaße, wie z.B. die Anzahl der Arzt- und Krankenhausbesuche. Diese Informationen werden sowohl für die Kinder als auch für die Eltern wiederholt beobachtet. Außerdem wird der Tabakkonsum der Eltern als Proxy für Gesundheitsverhalten verwendet.

Die Ergebnisse zeigen, dass es einen signifikanten Zusammenhang zwischen der kindlichen Gesundheit und der Gesundheit ihrer Eltern gibt: Dieser ist allerdings weniger zwischen anthropometrischen Maßen beider Generationen festzumachen. Außerdem zeigen die Ergebnisse, dass die „,intergenerationale Transmission“ von Gesundheit am größten für die Gesundheitsmaße ist, die auf Einschätzungen der Mütter basieren.

Damit unterstreichen die Analysen einmal mehr die Bedeutung des mütterlichen Wohlbefindens für das gesundheitliche Wohlbefinden ihrer Kinder. Letzteres lässt sich demnach über eine Stärkung des mütterlichen Wohlbefindens in Hinblick auf die physische und psychische Gesundheit der Mütter steigern. 


\title{
The Intergenerational Transmission of Health in Early Childhood
}

\author{
Katja Coneus*, C. Katharina Spiess ${ }^{\dagger}$
}

September 10, 2008

\begin{abstract}
The prevalence and importance of children's physical health problems have been increasingly recognized in recent years. Physical health problems of children such as obesity, motor impairment and chronic diseases cause social costs. Further, they can lead directly to adult physical health problems, which cause additional social costs. This paper examines the intergenerational link and transmission of both maternal and paternal health on children's health in Germany. We investigate this issue using data from the German Socio-Economic Panel (SOEP), making particular use of the mother and child questionnaires. These data allow us to capture a broad set of health measures: anthropometric, self-rated health and "more objective" health measures. The results indicate significant relationships between parental and child health in the first and third year of life. In order to take into account the endogeneity of parental health, we estimate fixed effect models. Overall, we find, controlling for parental income, education and family composition, that parents who experience poor health have children with significantly poorer health. For example, the father's body mass index (BMI) is a predictor for their children's BMI. Mothers who consider their health as good, have also healthier children.
\end{abstract}

*Centre for European Economic Research, Mannheim.

${ }^{\dagger}$ DIW Berlin/FU Berlin. Corresponding author: DIW Berlin (German Institute for Economic Research) Mohrenstraße 5810117 Berlin/Germany. phone: +49-30-89789-254, E-mail: kspiess@diw.de. 
Keywords: Intergenerational transmission, child health, parental health, early childhood.

JEL-classification: I1, I12, J13

Acknowledgements: We gratefully acknowledge support from the Leibniz Association, Bonn under grant "Noncognitive Skills: Acquisition and Economic Consequences". We thank Irene Bertschek, Andrea Mühlenweg, Friedhelm Pfeiffer and the participants of the 8th International German Socio-Economic Panel User Conference (July 9-11) in Berlin for valuable comments on earlier drafts of this paper. 


\section{Introduction and Motivation}

In recent years, there has been a growing concern about children that suffer from physical health problems. The 2004 International Obesity Taskforce report (IOTF; 2004), for instance, states that approximatively 14 million children in Europe suffer from obesity, three million of whom suffer from adiposity. For Germany the Robert-Koch Health Survey 2006 reports 1.9 (0.8) million children between 3-17 years having obesity (adiposity). Compared to the reference cohort 1985-1999 the share of obese (adipose) children increased by 50 percent (100 percent) (Kurth and Schaffrath; 2007). Moreover, in recent years a shift from acute to chronic diseases, such as asthma or neurodermatitis, and a shift from somatic to psychical diseases known as "new morbidity" are newly discussed in the medical literature, for example Kurth et al. (2008).

A special health survey among children in Germany showed that $54.1 \%$ of the parents rate the health of their children as good, $39.2 \%$ even as "very good" (Kurth et al.; 2008). In Germany $7.5 \%$ of all girls and $10.3 \%$ of all boys between 11 and 17 years have allergic coryza. $3.5 \%$ of all boys in this age group and $2.5 \%$ of all girls are reported to have asthma (Robert-Koch-Institute 2006). In general children's physical health problems such as obesity, bronchitis, vision and motor impairments cause social costs, primarily in the sense of health costs. Moreover, children's health problems can lead directly to adult physical health problems, which cause additional social costs.

In economics there is one research strength which analyses the link between child health and parental background factors, such as education and income. For such research see for instance, Duncan et al. (2007), who uses data from three countries to examine the relationship between parental education and child height. Other studies for example, Currie and Stable (2003), Case et al. (2002), and Currie and Stabile (2006), focus on the child-health-income gradient. The results were re-examined in a most recent paper by Case et al. (2008). They intend to explain differences found between income gradients in American and English children's health. As for England, new analyses indicate that income plays a larger role in protecting children's health from the effects of chronic conditions. In general this group of studies investigates the differences in the allocation of household resources on child health. 
Another body of research attempts to quantify the effects of early infant health on a person's future health, education and social outcomes. This economic literature recognizes that physical health problems can impede children's human capital formation over the whole life cycle, see for example Almond et al. (2005), Currie and Stable (2003), Case et al. (2005), Ding et al. (2006), Currie and Hyerson (1999), Currie and Neidell (2005) or Black et al. (2005). Most of these studies focus on the correlation between low birth weight (LBW) and later outcomes. Currie and Hyerson (1999), for instance, find that LBW has significant long-term effects on self reported health status, educational attainments and labor market outcomes. Other studies such as Miller et al. (2005) suggest that such a mechanism is rather weak. Aside from LBW, there has been little research on the long-term consequences of other specific health conditions. For one exception see Currie and Stabile (2006), who examine the long-term consequences of Attention Deficit Hyperactivity Disorder (ADHD). Salm and Schunk (2008) do find for Germany that childhood health conditions explain $18 \%$ of the gap in cognitive ability and $65 \%$ of that in language ability. Overall, this research shows that controlling for parental income, education and social class, children who experience poor health have significant lower educational attainments, a poorer health and a lower social status as adults.

The link between the physical health of the parents and the children's physical health, however, has received little attention in the economic literature. This paper focuses on exactly this issue, examining the intergenerational link of health between parents and children and the health transmission from parents to children in Germany. ${ }^{1}$ Parental health might influences child health either because parents and children share the same genetic endowments and/or through "behavioral effects" respectively "environmental effects".

We concentrate our analysis on the link and transmission process between parental

\footnotetext{
${ }^{1}$ In contrast to other studies related to intergenerational processes of social outcomes, we explicitly distinguish between intergenerational links and intergenerational transmissions. The former means simply the association between parental and child health in a cross-section context. The transmission of health between generation identifies the relationship between parental and child health in a causal manner in a fixed effect model context.
} 
health and the health of children in their first three years of life. The early years are a crucial period for children's health and skill formation. This is even more true, as there is empirical evidence showing that early child health affects skill formation (for a most recent study, see Cawley and Spiess (2008)).

Our paper expands on the results of previous health studies in the following ways: First, we focus on the intergenerational link and transmission of both, maternal and paternal health on children's health in early childhood. Second, we examine the effects of a range of parental health measures on a range of children's health measures. Finally, in order to take into account the endogeneity of parental health, we estimate time fixed effect models.

The paper is organized as follows: After describing potential links and transmissions of health we summarize previous studies on these issues in chapter 2. Chapter 3 describes our data, methods and variables. The next chapter presents our results, first on the link between parental health and child health and then on the transmission of parental on child health. We conclude with a discussion and prospects for future research. 


\section{The intergenerational transmission of health}

As it is summarized by Ahlburg (1998) studies on the intergenerational transmission of health have mostly been carried out by genetic epidemiologists, who have sought associations between genes and specific diseases. Furthermore, there are estimates of the intergenerational correlation of the lifespan, which can be considered as the ultimate output of the health production function. Estimates of health correlation over the life-cycle between generations have been used to support a strong genetic component of longevity (see for a summary and critical reflection of theses studies Ahlburg (1998)).

Thus, there are only few studies analysing transmission of health between generations, where the children have not yet reached adulthood. Apart from this, most studies on child health and its socio-economic determinants do not control for parental health (see for instance, Thomas (1994) or Case et al. (2005)). This lack is partly driven by a lack of data. Most surveys that collect information on child health do not have information on parental health. Further difficulties can also arise because health is a multidimensional and time-variant measure, compared to other socio-economic measures such as education. We use various health measures at different points in time for both, children and parents to handle these difficulties in our study.

There might be a close link between parental health and child's health for several reasons: First, there is a genetic dimension. For this reason, it is important to observe different health dimensions of both, maternal and paternal health. Second, there is an "environmental effect", as children grow up in the same "shared" and "non-shared" environment as their parents. Parents have a direct and indirect influence on what their children obtain in terms of health care and medical treatment. They can invest directly in the health of their children through the use of inputs such as nutrition and (medical) health care, and by avoiding unhealthy behaviors such as smoking and drinking alcohol (see for example, Rimal (2003) or Wickrama et al. (1999)). These investments are strongly related to labor supply and household budget constraints. On the one hand, constraint families may be less able to provide medical care and nutritious food. On the other hand, parents who work full time and therefore have less financial constraints may spend less time 
with their children, which can also affect children's health. ${ }^{2}$

Apart from this, unhealthier parents may exhibit unhealthier behavior such as smoking or regular alcohol consumption that can be detrimental to child health. In addition, poor parental health reduces labor supply and reduces family income, and thus can have an indirect effect on child health. Moreover, unpredictable effects of the parents with respect to their health, for instance accidents, could effect the health of the children, in the sense that parents who are disable due to an accident have less resources (financial and time) to invest in the health of their children. Finally, the health of parents and children might be affected by common but unmeasured environmental factors, resulting in a correlation between their health levels. Overall, it is obvious that there are various mechanisms how parental health might be linked or even transmitted into child health. However, it is not easy to disentangle them.

Until now there are few economic studies which focus on different aspects of child and parental health. The work by Currie and Moretti (2005) is an example for a study on intergenerational health links. They examine intergenerational correlations in birth weight for Western industrialized countries. ${ }^{3}$ Based on the data on individual birth records from California they show that there is a strong intergenerational correlation between the mother's and the children's birth weight using grandmother fixed effect models. They also show that the family income at the time of mother's birth is also a predictor of LBW and that there is an interaction between maternal LBW and poverty in the production of LBW. Together their findings suggest that intergenerational correlations in health could play a role in the intergenerational transmission of income. Parent's income affects child health and health at birth affects future earnings.

Case et al. (2002) analyse parental health as a determinant of children's health. The authors use US data from the National Health Interview Survey (NHIS) 1986-1995 and the Panel Study of Income Dynamics (PSID), which cover self-rated

\footnotetext{
${ }^{2}$ Mahler (2007) for instance, found that a higher labor supply of the mother increases the probability of the child to be obese.

${ }^{3}$ Note, there are various studies regarding birth weight. However, to the best of our knowledge only this study looked at birth weight between generation.
} 
health measures rating the health of the children and the parents on a scale from $1=$ excellent to $5=$ poor. They find large effects of parent's health on children's health. If a child aged 0-3 has a mother in very good or excellent health, his or her chance of also being in very good or excellent health rises by $27 \%$. The corresponding increase related to very good or excellent parental health is $16 \%$. Moreover, maternal health is more strongly associated with child health compared to paternal health, which is consistent with the idea that women in worse health bear less healthy children, or that women in poor health are less able caregivers.

Another most recent study by Goode et al. (2008) investigates the possibility of intergenerational transmission of unhealthy eating habits from parents to adult children. Their regressions, which are based on the 2003 Scottish Health Survey, suggest that paternal history on eating habits has no impact on either sons or daughters and maternal history on eating habits influences negatively the eating behavior of daughters. The intergenerational transmission of unhealthy eating habits appears to be more intense amongst lower household income individuals.

On the basis of anthropometric health measures the links and transmissions between child and parental health are also investigated in developmental countries. Kebede (2003) for instance, uses data from rural Ethiopia in the period 1994-97. He uses the height as a measure for long term health and estimates fixed effects models on children's height. Beside other explaining variables parents height is highly significant in all specifications. They conclude that the correlation between child and parental health is mainly explained by genetic inheritance than by behavior. Bhargava (1994) uses a data set from a specific region of the Philippines during 1984-85. As health measures he uses the height, weight and BMI (Body Mass Index) of the child and the parents. Estimating dynamic model shows that parental - in particular maternal - health has large effects on child health.

Studies in other social science disciplines, such as psychology and epidemiology also contribute to the discussion of intergenerational health and health behavior respectively. ${ }^{4}$ Rimal (2003) estimates a model of dietary behaviors based on adults ${ }^{6}$

\footnotetext{
${ }^{4}$ For non-economic studies on the correlation of birth weights between generations, see for instance Coutinho et al. (1997), Collins et al. (2002) or Conley and Bennett (2000).
} 
and children's interpersonal, intrapersonal, and communicative factors when children are 12-19 years old. Adult's interpersonal determinant of dietary behavior predicted corresponding children's health measures. Wickrama et al. (1999) investigate if parents' health risk behaviors influence adolescent's health risk behaviors. Parents' ${ }^{6}$ health risk behaviors were transmitted to adolescents both at the lifestyle factor level and the unique component level. Brook et al. (2002) examine the intergenerational transmission of risk factors for problem behaviors across three generations. The investigation provides evidence for a longitudinal, intergenerational process whereby the grandmother-parent relationship and the parent's personality and behavioral attributes are transmitted across generations through their association with the parent-child relationship. Marshall et al. (2007) investigate the international transmission of health beliefs in somatoform disorders. Children of parents with somatoform disorder scored higher on bodily preoccupation and disease phobia scales and their health beliefs showed similarities to the beliefs of their parents.

\section{Sample, variables and methods}

\subsection{Sample}

The data used for this study is the German Socio-Economic Panel (SOEP). For Germany, it is a representative national longitudinal data set that surveys households and individuals beginning in 1984 (see Wagner et al. (2007)). ${ }^{5}$ It provides an informative database with a rich set of indicators of both parent's and children's characteristics. Since 2003, detailed information on the health of children has been integrated into the SOEP by an additional questionnaire for mothers of very young children. This questionnaire is addressed to all mothers who gave birth to a child in the year of survey or the year before: The age of the child of mothers answering this questionnaire varies between 0 and 18 months. The questionnaire provides information on health issues of these children.

In 2005 an additional questionnaire on 2-3 year olds was introduced. The agespecific questionnaire again contains health information of the 26-42 months old children. Moreover, information on parent's physical health, education, family

\footnotetext{
${ }^{5}$ See http://www.diw.de/soep for more information on the GSOEP.
} 
income and composition, health insurance and municipality are also collected between 2002-2006. We merged the child information with the parental information. Based on these two age-specific questionnaires, we consider three samples: First a pooled cross section samples of children aged between 0-18 which amounts to 678 newborns born between 2002-2006, Second: a cross-section of 26-42 months old which amounts to 376 children born between 2002 and 2003. ${ }^{6}$ Third: a panel data set with 400 2-3 years old children whose mothers have been successfully interviewed two times, in the first and third year of a child's life in 2002/2003 and $2005 / 2006$.

\subsection{Health measures}

Child health. Finding appropriate measures of a child's health status is a challenge. Health has many dimensions, such as mental, physical, chronic conditions, environmental exposures, nutrition and injuries. In developing countries, infant mortality rates, anthropometric measures and indicators for vaccination provide a guide to child health. Studies for Western industrialized countries use LBW as an indicator of poor health at birth (see studies cited in chapter 1). Much less is known about the predictive power of reported health measures in early childhood. Case et al. (2002) use alternative measures of children's health, including bed days and hospitalization episodes and find that the reported health status correlates strongly with children's chronic conditions. As there is still no operational global definition of child health, it might be useful to use various measures, once they are available.

This is an advantage of the data we use. The SOEP allows us to observe different types of health measures for the children (for other SOEP based studies using similar child health measures, see for instance, Dunkelberg and Spiess (2008) and Cawley and Spiess (2008)). Besides anthropometric measures such as weight, height, BMI and obesity (computed), ${ }^{7}$ we have self-reported health measures:

\footnotetext{
${ }^{6}$ In some models we exclude individuals younger than three months from our regression, since a child's health information refer to three months after births. Here we observe 568 children. For a more detailed discussion of robustness see chapter 4 .

${ }^{7}$ Based on gender-specific age percentiles (Poskitt; 1995) we define children as obese or not. We
} 
Information on children's doctor and hospital visits three months after birth for the younger children. For the older children (2-3 years old), we have information about how often they visited a doctor in the last three months and how often they were in the hospital in the last 12 months. For both relevant age groups of our study information on special disorders of the child, for example, motor impairments and asthma are available. These self-reported information on the utilization of the medical care system and particular disorders can also serve as a proxy variable for objective health (for such an approach see Schwarze et al. (2000)). Other studies, such as Baker et al. (2001), use the term "self-reported, more objective health measures" for such health information in contrast to self-rated health measures. We adapt this term and for simplicity reasons we us the term "more objective" health measures in the following. ${ }^{8}$ Apart from these "more objective health measures", we use self-rated health measures too: The mothers in the SOEP were asked in both mother-child-questionnaires whether they are worried about their child's health. They could specify to what extent the statements apply, ranging from "applies fully" to "does not apply". Given this broad set of health measures, we do several estimations, using anthropometric, more objective and self-rated health measures.

Parental health. As parental health we also observe various health measures (compare, Schwarze et al. (2000)). They cover anthropometric measures (BMI and computed obesity for example, (Poskitt; 1995)), as well as "more objective" and self-rated health measures. In accordance with the "more objective" child health measures, the number of doctor visits in the last three months and the nights spend in hospital in the last 12 months are used. The SOEP data also contain a self-rated health measure of the parents: ${ }^{9}$ Individuals were asked how they assess their own current health status, using a scale from $1=$ (very good) to $5=(\mathrm{bad})$. Further, mothers of newborns were asked an additional question in the mother-child questionnaire, how they rate their mental and physical health three months after pregnancy on a scale from $1=($ very good $)$ to $4=($ very bad $)$. Finally, we

are aware of the finding that the BMI is a poor measure of fatness, as it does not distinguish fat from muscle (Burkhauser and Cawley; 2008). However, the BMI is the only measure of fatness available in the SOEP.

${ }^{8}$ Doing so, we are aware of the fact that our "more objective health measures" are only proxies for really objective health measures taken by medical experts.

${ }^{9}$ In the main SOEP self-rated health is measured by an internal widely accepted scale. 
use indicators of parent's health behavior: We do use the information, if the parents are smoking. Furthermore, anthropometric and "more objective health measures" might also assess the health behavior of adults: A high BMI, for instance, might be a proxy, in part, for the care parents take with their own health. A lack of any doctor's visit by a mother might be a signal that the mother has not gone to the annual check-up generally recommended to women in Germany.

Overall we use a wide range of health measures, "more objective" and selfrated ones. One might argue that self-rated health measures are not valid health measures. However, the empirical health literature has shown that self-rated health measures are highly correlated with "more objective health measures", such as the rate of hospital or physician visits, or mortality (see for instance Singh-Manoux et al. (2007) or Schwarze et al. (2000), who show the same correlation as Singh-Manoux et al. (2007) on the data set used in the present study).

Table A.1 reports descriptive statistics for all children's and parental health measures. In accordance with the two mother-child-questionnaires (first year of life and 2-3 year-olds), we distinguish summary statistics for both age-groups. The 3-18-month olds had an average BMI of 12.71, which increased on average to 16.03 after two years. The share of obese children is increases from five percent for the younger children to nine percent after two years. In younger age groups only eight percent of the newborns have any disorder such as motor and visual impairments. Later on, the percentage is five times higher, in part because more mothers report that their children have asthma or bronchitis. In contrast, the average numbers of doctor visits between the two age groups remained nearly unchanged. The hospital visits of children decreased from 1.43 nights in the first age group to 0.19 nights two years later. Based on the information on doctor's visits and hospital visits we computed a variable for children's general health called "medical assistance", which is the sum of the number of doctor and hospital visits within a particular period. The underlying idea behind the generated variable is the fact that hospital stays and doctor visits are not independent. ${ }^{10}$ In both waves nearly $60 \%$ of all mothers valuated the health of their child as "very good" or "good".

\footnotetext{
${ }^{10}$ The correlation coefficient is 0.32 .
} 
The average BMI for both mothers and fathers varies slightly in both waves between 23.20 and 25.41. In our sample, 11 (12) percent of mothers (fathers) are obese when their children are 2-3 years old. Between the two age groups of children the average number of doctor visits and nights spent at the hospital decreased among mothers. Moreover, mothers and fathers differ with respect to smoking. When children are 3-18 months old, the share of smoking fathers is nearly twice as high as the share of smoking mothers. But the percentage of mothers who do not smoke and have very young children is four percent lower than for mothers with older children. It may be that mothers interrupt smoking during pregnancy and start smoking again if their children are a bit older. Other health measures are similar for mothers and fathers. The mothers' own health assessments are nearly unchanged between the two age-groups. ${ }^{11}$

\subsection{Child and family characteristics}

Summary statistics for child characteristics and the family background that might also affected the child's health are reported in Table A.2. Among the child-related variables, there is the age of the child in month, the gender of the child and the share of children growing up with siblings. Other studies (for instance, Duncan (1994)) have shown that gender differences in the resource allocations into child health, which might reflect both technological differences in child rearing and differences in the preferences of parents. Mothers allocate more resources to their daughters and fathers channel resources towards their sons.

Control variables related to the parents cover the age of mother and the father at the time of birth, their educational background, the household structure (single or non-single parent), the migration background of the mother, equivalence household income (in 1000 Euro). They further cover if parents have a private health insurance and a variable indicated if the household lives in a municipality respectively rural area.

\footnotetext{
${ }^{11}$ We do not observe father self-rated health measures, because mothers and not the fathers were requested to assess the health of their child.
} 
The educational background of each parent is measured by three dummies: university degree, occupational degree versus no degree (reference category) at all. For these variables other studies found differing effects. Case et al. (2005), for instance, do control in their study for the effects of childhood health on adult health for the mothers and the fathers education and SES (Socio-economic status). By age 33, maternal education has become strongly associated with a better health status of the child. Indicators for the fathers school-leaving ages are not jointly significant at either age 33 or 42. Case and Paxson (2001) show that for children 1-16, mothers' education is a significant predictor of the child having had a routine doctor and dentist visit in the past 12 months, and with having a regular place for usual medical care and sick care. They find no significant correlation between fathers' education and routine doctor's visits or having a place for routine or sick care.

We take into account whether the child is raised by a single parent or not. In these cases parents can not share child rearing efforts with a partner, which might result in less time they can invest in the health of their children. Furthermore, we control for the migration status of the parents, which might capture different cultural attitudes towards the investments in the health of children. Our income measures cover the equivalent income of a household, which takes the various household sizes into account. The literature had extensively examined the effect of income, as one of the important economic variables affecting child health (see for instance, the very new analysis by Case and Paxson (2008)). First, income levels affect the amount of resources households devote for nurturing children. Second, health-related behavior of people (like smoking, alcohol consumption, health care) is usually systematically correlated with levels of income. Third, in addition to the absolute levels of income, health is affected by income inequality - particularly in industrialized countries. Lower ranks in the distribution of income probably raise psychosocial stress that negatively affects endocrine processes and immunity. Although we control for smoking we can not disentangle all these various income effects. For a detailed study about income is effect on child health, see the analysis by Case et al. (2002). ${ }^{12}$

\footnotetext{
${ }^{12}$ Apart from this, we do not control for the employment status of the mother, as this might be endogenous to child health. As it is shown in various studies, the employment status of mothers might influence child health as the mothers have more financial resources to invest in child health. This effect is covered by the income variable we use, at it covers the total household income. Apart
} 
A dummy variable indicating whether either the mother or the father or both have a private health insurance or not, does allow us on the one hand to test, if children who have access to higher quality care might have a better health status. On the other hand, these variables might capture the effect that parents with a private health insurance have a higher frequency of doctor visits as more cost-types are covered by their health insurance. The study by Case et al. (2002) shows that children with insurance - either private insurance or Medicaid - are in significantly better health. Although all children in Germany have some kind of health insurance, it might be argued in a German framework that children who have a private health insurance via their parents have access to higher quality care, as in principle private health insurances in Germany pay, for instance, the costs of a treatment by a head physician. ${ }^{13}$

Furthermore, the municipality size should cover the effect, that families living in municipalities might have a better access to relevant health infrastructure. On the other hand, it might be that children living in rural areas live in an environment which is less polluted. As it is shown by Currie and Neidell (2005) this affects child health as well. Which effect is stronger is an empirical question, however. ${ }^{14}$

\subsection{Econometric Model}

Given the variety of health measures in our sample, we group them and test the link and transmission between parental and child health using different groups of health measures. A first group of models uses anthropometric health measures for children, mothers and fathers. The second group of models use the so-called more objective health measures again for the children and their parents only, while the last group

from this, employed mothers might have less time to invest in the health of their children, or the other way around, due to the illness or disability of their child mothers can not or work only reduced hours. For a German study on this, see for instance, (Dunkelberg and Spiess; 2008).

${ }^{13} \mathrm{See}$ for a description of the German health insurance system http://www.bmg. bund.de/cln_040/nn_617002/EN/Health/health-insurance.html, download: June 15th 2008).

${ }^{14}$ Another argument might be that one should control for possible genetic ties. Case et al. (2002), for instance use the information if it is an adopted or biological child to test the hypothesis on genetic ties. Their results cast doubt on the simple genetic story. In our study there are only 4 adopted children, but if we exclude individuals with missing values from analysis we have no longer adopted children in our sample. 
of estimations is supposed to use self-rated health measures. However, as the child related more objective health measures are reported by the mother they might not be entirely objective. Given this potential bias we estimate models on important more objective and self-rated child health measures using only maternal self-rated health measures as independent variables. All models contain the parental health behavior.

Equation (1) presents the link between health of parents and children:

$$
\text { Health }_{i}=\alpha+\beta \text { Health }_{j i}+X_{j i} \delta+Y_{i} \gamma+u_{i}
$$

where Health H $_{i}$ is a measure of child i's health in early childhood, which covers anthropometric, more objective and self-rated health. Health $h_{j i}$ denotes a vector of parental (j) health (it also includes parental health behavior of the child i). $X_{j i}$ is a vector of parental characteristics that includes education, household income, family status, health insurance, age, nationality and municipality size of the child i. $Y_{i}$ is a vector of children characteristics that includes sex, siblings and age. At first, we estimate cross section models for both age-groups and all different health measures. Therefore, we control for many family background variables and child characteristics.

Since unobserved, time invariant characteristics, such as unobserved parental health behavior, genetic components or time preferences may affect both, parent's and child's health, we replicate cross-section results in a fixed effect framework.

$$
\text { Health }_{i t}=\alpha+\beta \text { Health }_{j i t}+X_{j} \delta+Y_{i t} \gamma+f_{i}+u_{i t} .
$$

In contrast to equation (1), in equation (2) we take into account an individual fixed effect $f_{i}$. Within this model we analyse the intergenerational transmission of parent's health on child health, conditional on time-variant family background variables, captured in $X_{j i t}$. The coefficient on parental health $\beta$ is our parameter of interest. The parameter can be used to test a variety of hypotheses. First, $\beta$ provides information on whether children of parents with poor health also experience poor health ceteris paribus in early childhood. Second, the coefficient $\beta$ can be interpreted as a health gradient. A high coefficient indicates a strong transmission of health characteristics from parents to children. Finally, the coefficient $\beta$ can be decomposed into the impact of mother's health and father's health on the child's health. We estimate FE models to identify $\beta$. 
First differencing:

$$
\Delta \text { health }_{i t}=\beta \Delta \text { health }_{j i t}+\Delta X_{j i t} \delta+\Delta Y_{i t} \gamma+\Delta u_{i t}
$$

After first differencing (equation (3)), we assume that the conditional mean independence assumption holds (equation 4, 5). Conditional mean independence

$$
E\left(\Delta u_{i t} \mid \Delta \text { health }{ }_{j i t}, \Delta X_{j i t}, \Delta Y_{i t}\right)=0 \quad \forall t=1,2 .
$$

implies:

$$
E\left(\Delta u_{i t} \mid \Delta \text { health }_{j i t}, \Delta X_{j i t}, \Delta Y_{i t}\right)=0 \quad s \leq t
$$

This implies that the error terms are uncorrelated with $\Delta$ health $h_{j i t}, \Delta X_{j i t}, \Delta Y_{i t}$ within one period (4) and are uncorrelated between different periods (5).

\section{Results of the Health Regression}

Presenting our results, we start with the regression results on the cross-sectional samples of the two age-groups we can observe in our data: We start with the age group covering children 0 (3) to 18 months of age, followed by children 26 to 42 months of age. After presenting the results on the link between health measures, we present the results of the fixed effect models on the intergenerational transmission of health. The following tables cover the results with respect only to the health measures. The entire regression results are presented in TableA.3 - Table A.8.

\subsection{Cross section for 2 age-groups: the intergenerational link between health}

Children 0-18 months of age. The first columns of Tables 1 - 3 cover the results for the younger age group of children. As it is shown there is no statistically significant link between the anthropometric health measures of parents and children (see Table 1). ${ }^{15}$ Moreover, the results indicate a positive link between having siblings and the BMI of the very young children. Finally, growing up in rural areas

\footnotetext{
${ }^{15}$ One explanation might be that the critical BMI values used is not appropriate-until now little is known about critical BMI values in early childhood that are related to other diseases later in life.
} 
is associated with a lower BMI and the probability of being obese.

The estimations using more objective health measures (see Table 2) show that mothers who report more doctor visits for themselves report more doctor visits for their young children as well. With respect to a child's days in hospital, the results show a statistically significant and positive relationship with the father's doctor visit. Apart from this, smoking mothers have a significantly higher probability of having a child with reported disorder. Having a private health insurance increases the number of doctor visits and the extent of medical assistance a child receives three months after births. Furthermore, we find that boys are less healthy in early childhood compared to girls. This is in line with the existing literature related to the vulnerability of boys. Interestingly, older fathers have the less healthier children at 3-18 months.

With respect to self-rated health measures our results show that the mothers' reported mental and physical health status three months after pregnancy does matter (see Table3): The worse the reported mental and physical health state, the higher the probability that the child has some disorders. There is a statistically significant link between the mental state of the mother and the reported worries on child health: The better she rates her own mental state the less she worried about the health of her child. The mental and physical health of the mother is correlated with the number of doctor's visits of the child, too. This is true for the mental state of the mother and the number of hospital visits of the child as well as medical assistances of the child: The better the mother rates her mental (physical health) the healthier the child, if the mentioned "more objective" health measures are considered. Apart from this, health behavior matters, too: Smoking mothers have a higher probability of having a child with disorders. Furthermore, there is a statistically significant link between having a father who smokes and more worries by the mother about her child's health.

Children 26-44 months of age. The second part of Tables 1 - 3 cover the results for the older age group of children. For older children, there is no statistically significant relationship between the anthropometric health measures of the child and those of the parents (see Table 1). However, there is a link with respect to parent's health behavior. In line with the related literature we find that maternal 


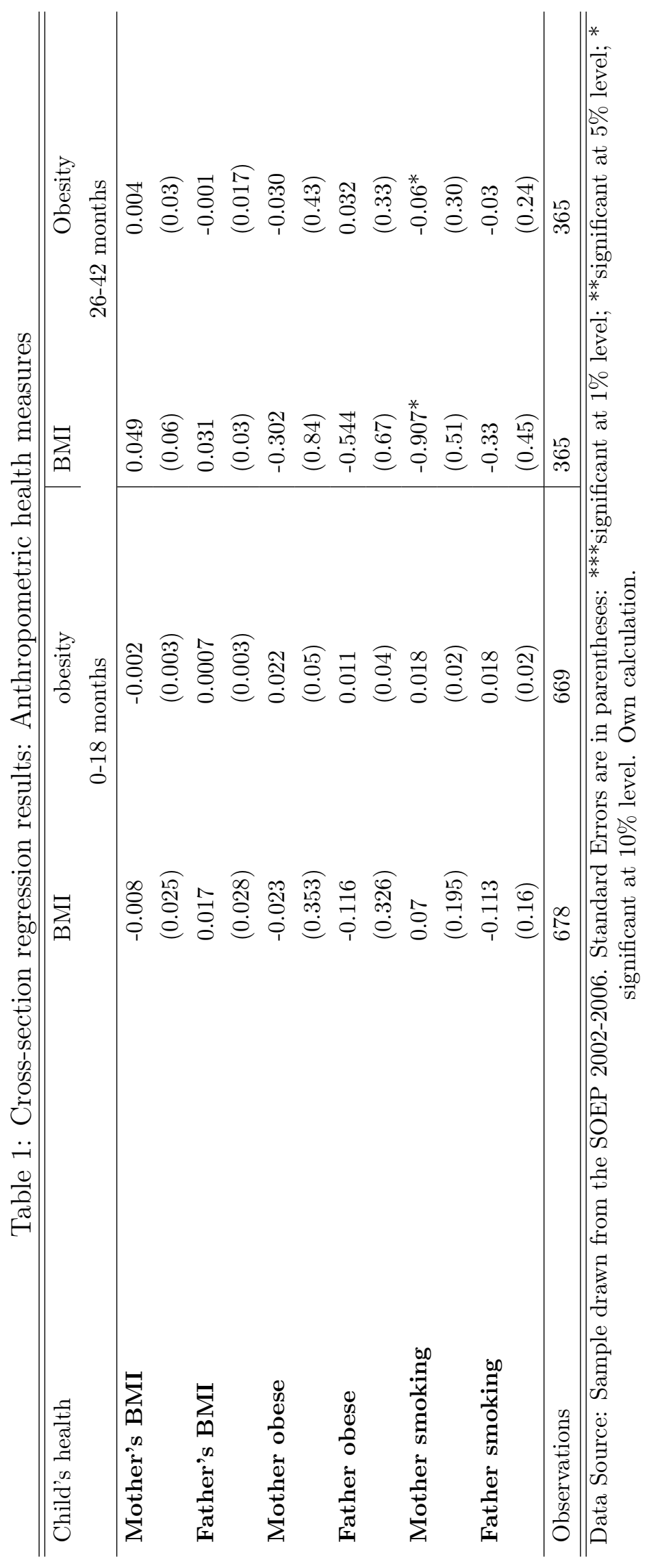




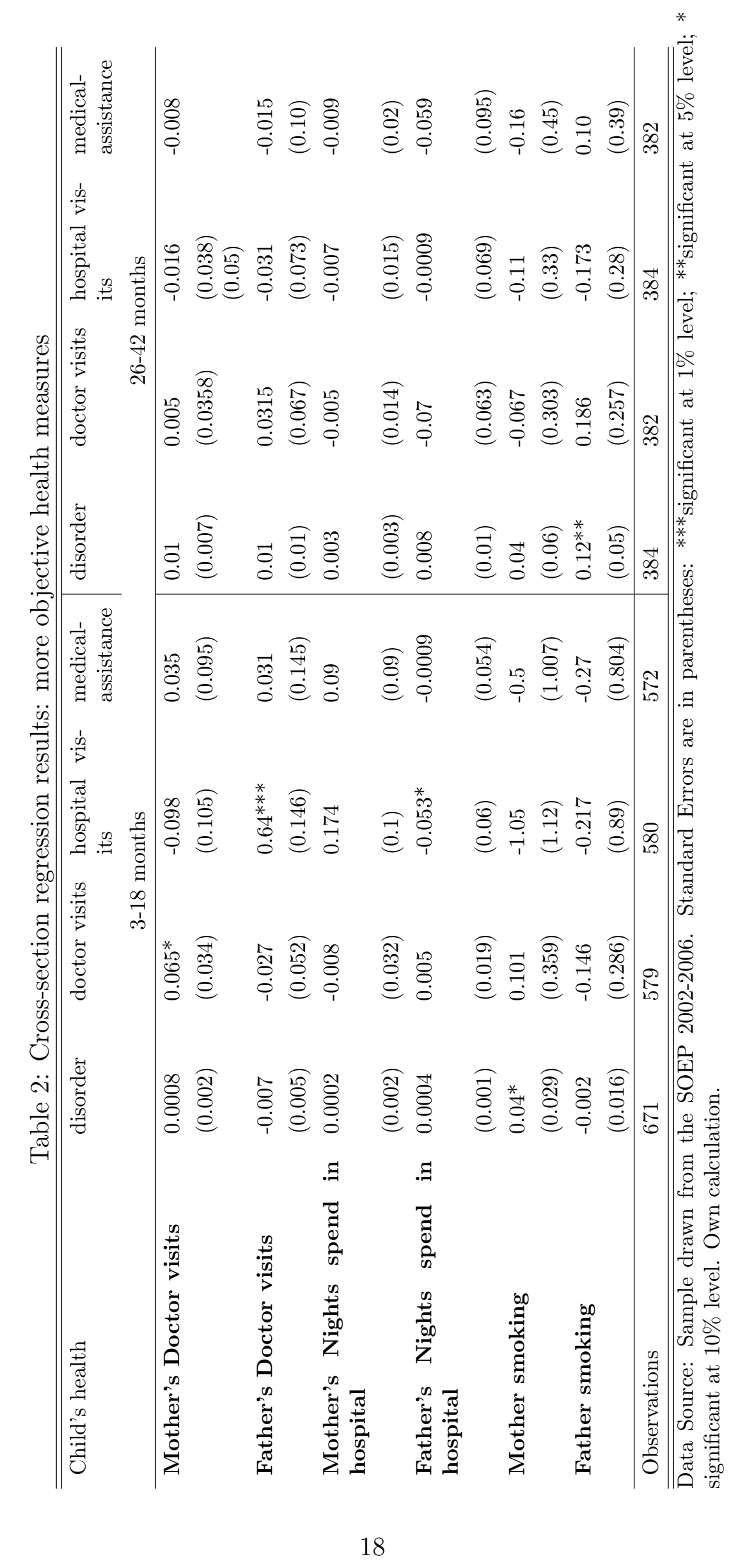


smoking leads to growth retardation of 2-3 year old children.

In contrast to the findings of the early age group, for the older children we find neither a link between the mother's more objective health and the child's more objective health nor between the father's "more objective" health and the child's "more objective" health, respectively (see Table 2). However, smoking fathers have a higher probability of having a child with any kind of disorders. Other control variables which are statistically significant are the child's sex, the fact of having siblings, the age of the father and his education, at least in some of the models.

With respect to self-rated health measures the results show a statistically significant relationship between the mother's self-rated health and child health (see Table 3): The more satisfied the mother is with her own health the less she worries about her child's health. The better the mother rates her own health the smaller the probability of having a child with disorders. Furthermore, the mothers who rate their own health better report a smaller number of hospital days for their child and less medical assistance for their child, at all. Again, the health behavior does matter: Fathers who smoke have a higher probability of having a child with disorders. Father's education and the age of the child are control variables with a statistically significant relationship to the child health measures we use. 


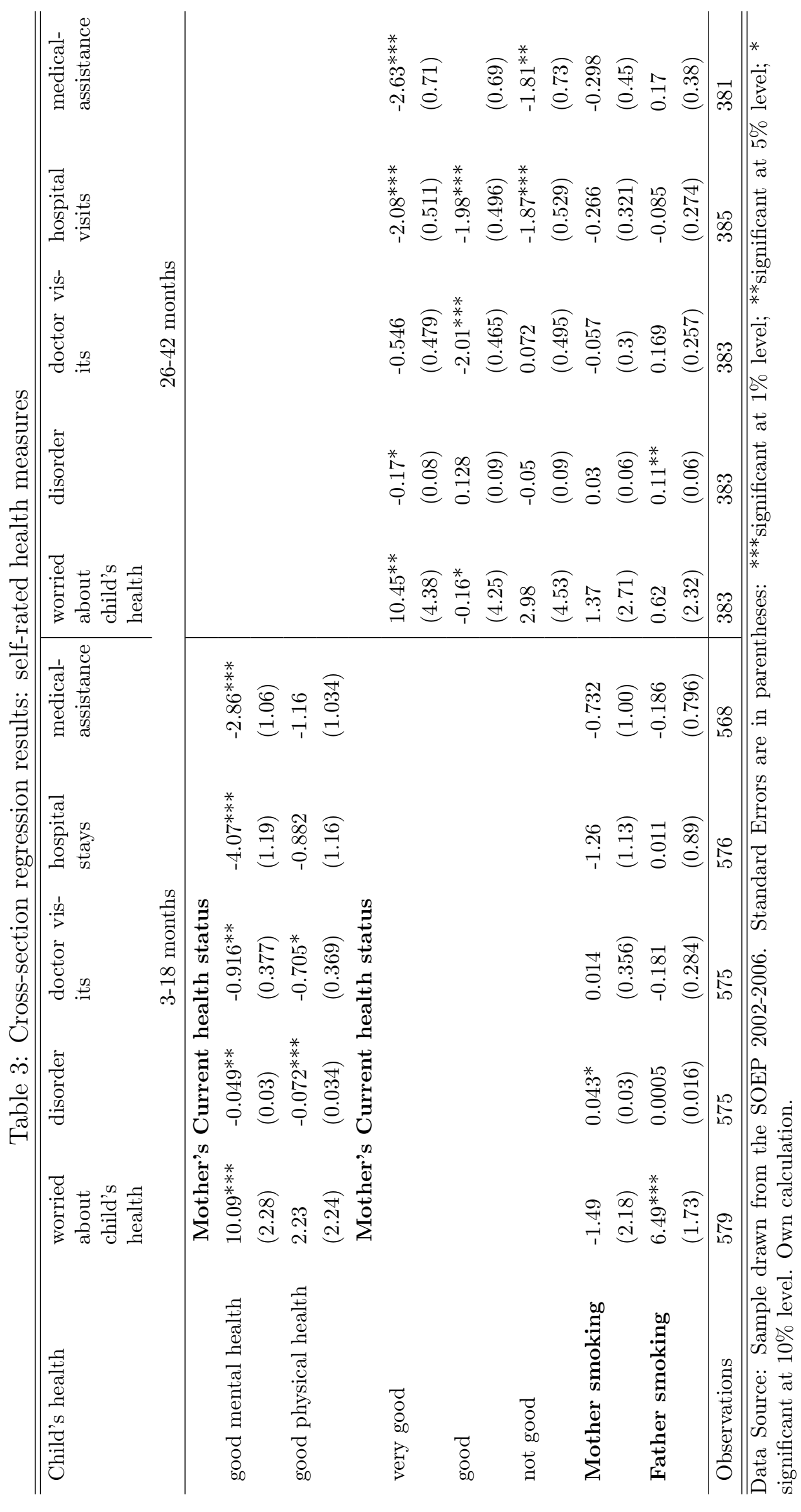




\subsection{Fixed effect models: the intergenerational transmission of health}

Overall, our fixed effect models show the following picture: In respect to anthropometric measures (see Table 4) there is a statistically significant effect of a father's BMI on his child's BMI: The higher the father's BMI the higher the child's BMI. Further, the probability of having obese children increases for obese mothers. We find a positive effect of child's age on BMI.

Table 4: Fixed Effects Results: Anthropometric measures

\begin{tabular}{lll}
\hline \hline Child's health & BMI & obesity \\
\hline Mother's BMI & -0.15 & -0.015 \\
& $(0.14)$ & $(0.01)$ \\
Father's BMI & $0.57^{* *}$ & 0.014 \\
& $(0.359)$ & $(0.026)$ \\
Mother obese & 1.24 & $0.26^{*}$ \\
& $(1.33)$ & $(0.13)$ \\
Father obese & -1.22 & 0.03 \\
& $(1.06)$ & $(0.11)$ \\
Mother smoking & 0.02 & -0.04 \\
& $(1.01)$ & $(0.10)$ \\
Father smoking & $-1.44^{*}$ & -0.02 \\
& $(0.85)$ & $(0.09)$ \\
\hline Observations & 400 & 400 \\
\hline \hline Data Source: Sample drawn from the GSOEP 2002-2006. Standard Errors are in parentheses: \\
**** significant at 1\% level; **significant at 5\% level; * significant at 10\% level. Own calculation.
\end{tabular}

With respect to more objective health measures we find, contrary to the cross section results, no influence of parental "more objective" health measures on child health, if we control for unobserved heterogeneity (see Table 5). Fathers' smoking behavior increases the probability of having a child with any kind of disorder, but at the same time it decreases the number of hospital stays. ${ }^{16}$ Among the control variables only the child's age has a statistically significant effect.

Again the models using self-rated health measures show significant relationships between maternal health and child health (see Table 6): Mothers who report a

\footnotetext{
${ }^{16}$ For this result we have no intuitive explanation.
} 
Table 5: Fixed Effects Results: more objective health measures

\begin{tabular}{lllll}
\hline \hline Child's health & disorder & doctor visits & $\begin{array}{l}\text { hospital } \\
\text { stays }\end{array}$ & $\begin{array}{l}\text { medical- } \\
\text { assistance }\end{array}$ \\
\hline Mother's Doctor visits & -0.0005 & 0.001 & -0.05 & -0.06 \\
Father's Doctor visits & $(0.005)$ & $(0.04)$ & $(0.09)$ & $(0.11)$ \\
& -0.01 & -0.04 & 0.17 & 0.13 \\
Mother's Nights spend in hospital & $(0.01)$ & $(0.07)$ & $(0.18)$ & $(0.21)$ \\
& 0.004 & -0.04 & 0.02 & 0.001 \\
Father's Nights spend in hospital & $(0.003)$ & $(0.04)$ & $(0.05)$ & $(0.11)$ \\
\multirow{3}{*}{ Mother smoking } & 0.007 & -0.024 & -0.23 & -0.25 \\
& $(0.01)$ & $(0.07)$ & $(0.19)$ & $(0.22)$ \\
Father smoking & 0.16 & 0.16 & 0.30 & 0.27 \\
& $(0.10$ & $(0.68)$ & $(1.78)$ & $(2.04)$ \\
\hline Observations & $0.16^{*}$ & 0.14 & $-3.23^{* *}$ & -3.06 \\
\hline \hline
\end{tabular}

Data Source: Sample drawn from the SOEP 2002-2006. Standard Errors are in parentheses: ${ }^{* * *}$ significant at $1 \%$ level; $* *$ significant at $5 \%$ level; ${ }^{*}$ significant at $10 \%$ level. Own calculation.

change in their self rated health status (in the direction of getting better), have a significant lower probability of having a child with disorders. The same is true when the mother rates her own health as very good: Then she worries less about the health of her child and the child has experienced less medical assistance. The father's smoking behavior does matter again and increases the probability of having a child with disorders. Among the control variables again only the child's age has a statistically significant effect.

Robustness. In addition to these estimations we did several robustness tests, mainly on different model specifications and subsamples. ${ }^{17}$ We divided our sample into boys and girls for investigating gender differences in health transmission from parents to child. From the literature it is known that mothers invest more in their girls compared to boys (Case et al.; 2002). For example, Thomas (1994) finds that parents' resource allocations can result in differentials in height that vary by the gender of the child. Fixed effect results indicate that the health gradient of the mother is in some health models higher for girls, while it is in some health models

\footnotetext{
${ }^{17}$ Estimation results of the various sensitivity analysis are available from the authors upon request.
} 
higher for boys. The same is true for the health gradient of the fathers. Altogether, the results show that there is no clear pattern in respect to gender differences.

Table 6: Fixed Effects Results: self-rated health measures

\begin{tabular}{llll}
\hline \hline Child's health & $\begin{array}{l}\text { worried about } \\
\text { child's health }\end{array}$ & disorder & $\begin{array}{l}\text { medical assis- } \\
\text { tance }\end{array}$ \\
\hline Mother's current health status & & & \\
very good & $8.88^{* *}$ & $-0.27^{* * *}$ & -2.30 \\
& $(4.39)$ & $(0.09)$ & $(1.91)$ \\
good & 6.14 & $-0.26^{* * *}$ & -0.65 \\
& $(3.92)$ & $(0.08)$ & $(1.72)$ \\
not good & 5.27 & $-0.27^{* * *}$ & -0.72 \\
& $(3.87)$ & $(0.08)$ & $(1.70)$ \\
Mother smoking & 4.53 & 0.12 & 0.48 \\
& $(4.53)$ & $(0.10)$ & $(2.02)$ \\
Father smoking & -6.36 & $0.18^{* *}$ & -2.54 \\
& $(4.28)$ & $(0.09)$ & $(1.86)$ \\
\hline Observations & 408 & 409 & 409 \\
\hline \hline
\end{tabular}

Data Source: Sample drawn from the SOEP 2002-2006. Standard Errors are in parentheses: *** significant at $1 \%$ level; ${ }^{* *}$ significant at $5 \%$ level; ${ }^{*}$ significant at $10 \%$ level. Own calculation.

Moreover, we estimate fixed effect models taking a potential "pregnancy effect" into account. Studying the health of mothers of very young children is difficult, as all health measures of the mothers of particular young children might be biased due to pregnancy or delivery. Altogether there are 36 cases where the mother's health measures could most probably be distorted by these events. 36 mothers were surveyed in the year they gave birth. For the mothers who gave birth in the reference year, we would, for instance, expect that the number of doctor visits is higher. So we exclude the 36 mothers whose child was born in they year when they were interviewed. Overall, this did not changed our results significantly.

Furthermore, there might be a potential "hospital effect" due to the delivery in a hospital. The "more objective" health measure of the mother and the child might be biased in the year of delivery if mothers gave birth in a hospital. However, if all children would have been born in a hospital then this health measures would not systematically differ between mothers. But for cases where children were born outside the hospital, the variable is systematically biased. Thus, in a further specifications we exclude mothers of children who were not born in a hospital. These are 13 children in our sample. Altogether the results are very similar compared to 
the non-restricted sample. The estimated coefficients slightly differ in size but not in sign and significant level of the health gradient.

\section{Discussion}

This paper contributes to the literature on intergenerational health links and transmissions by providing new evidence on the association between various health indicators for very young children on the one hand and various health indicators of their mothers and fathers on the other hand. Our cross sectional analyses show that there are significant links between the health of children and parental health measures, this is particularly true for the association between self-rated health measures of the mother and child health measures. There is still a positive correlation even if we control for a rich set of control variables. They are less relevant for anthropometric health measures. Moreover, there are more statistically significant health associations between generations if the health of very young children (children in their first year of live) is analyzed. The fixed effect models show that the transmission of health can mainly be measured on a statistically significant level if self-rated health measures are observed. Thus our results strongly support the importance of self-rated health measures, in particular if intergenerational links and transmissions are analyzed.

Moreover, the magnitude of the association differ with respect to child's health outcomes. Interestingly, the health gradient is in all relevant "more objective" health models larger between fathers and children compared to the health gradient between mothers and children. For example, if father's doctor visits increases by one day within the last three months the nights spent in hospital for very young children increases by 0.64 . An increasing of mother's number of doctor visits within three months increases child's doctor visits by 0.065 . In addition, the probability to obtain any kind of disorder increases by 12 percentage points if fathers smoke. In the same age-group we find no impact of maternal smoking on the child's health.

Concerning the correlations of the control variables, our study shows no significant correlation between household income and child health. Parental education, in particular paternal education, was only significant in a few models. These results are different to the few US American studies on intergenerational health links (see, 
in particular Case et al. (2002)). Further research on the correlation with income in particular, has to show if this is mainly true for different income measures or if it is the results of two very different welfare states, including different health systems, namely a universal health coverage in Germany opposed to the American system.

Our findings are significant because health is an important resource for the acquisition of skills in early life and it facilitates the acquisition of additional capabilities at later ages (Heckman; 2007). Given this association, it is a strength of this study that it analysis health in early childhood: First, the health of children 0-18 months of age, and second, the health of children of 26-42 months of age. Given the challenge to find appropriate health measures it is another advantage of this study, that we can use three groups of health measures, anthropometric, more objective ones and self-rated ones. Moreover, we have a proxy for health behavior, namely the smoking behavior of mothers and fathers. All these health measures are observable for both parents, the mother and the father. To our knowledge, this is the only study based on a representative sample using so many alternative health measures for children, mothers and fathers.

Furthermore, our analyses allow us to make causal inferences: Given the panelcharacter of our data, we can estimate fixed effect models. Thus the results can be interpreted as transmissions - and not only as links - of health. Given these fixed effect results the health of the child- both the "more objective" and the self-rated health- is mainly driven by mother's self-rated health. In addition, the results indicate that paternal smoking during the years of early childhood increases the probability of any kind of disorder of the child by 16 percent, indicating a more stronger health gradient in comparison to the cross-section results.

Nevertheless, the study has limitations: The health measures of the child are assessed by the mother rather than by professionals. Weight, height and all other paternal health indicators are reported by the mother or the father. Although several studies conclude that, for instance, parental reports of child weight are sufficiently accurate to be used in research (for example, Goodman et al. (2000)), and although maternal reporting error of child weight is expected to be small in the SOEP because virtually all children had recent medical check-ups, such reporting 
error is likely to bias coefficient estimates. ${ }^{18}$

Besides, our results do not allow disentangling the effects behind an intergenerational transmission of health in a strict sense. We cannot separate "biological programming" from "environmental effects". However, given the intergenerational links of health in the first year of a child's life, there is some evidence that biological issues matter as "environmental effects" literally had not so much time to occur as with older children. However, the links were strongest for self-rated health measures, which might be an argument against this, if they are driven by environmental and biological factors themselves. Independent of this further research covering biometric measures might help to disentangle such effects.

Given the results on the intergenerational transmission of health and the strong effects of self-rated health measures, our results underline the importance of mothers' well being with regard to child's outcome measures. From a policy point of view one might argue that - given these results - it is effective to support mothers' mental and physical well-being if it is the political goal to increase child health.

\footnotetext{
${ }^{18}$ The German health system offers preventive medical check-ups for young children on a regular basis starting at birth. These check-ups are free of charge and are documented in a medical record booklet that is kept by the family.
} 


\section{References}

Ahlburg, D. (1998). Intergenerational Transmission of Health, AEA Papers and Proceedings 88 (2): 265-270.

Almond, D., Chay, K. and Lee, K. (2005). The Cost of Low Birth Weight, Quarterly Journal of Economics 120 (3): 1031-1083.

Baker, M., Deri, C. and Stable, M. (2001). What do Self-Reported, Objective, Measures of Health Measure?, NBER Working Paper.

Bhargava, A. (1994). Modelling the Health of Filipino Children, Journal of the Royal Statistical Society, Series A 157 (3): 417-432.

Black, S. E., Devereux, P. J. and Salvanes, K. (2005). Why the apple doesn't fall far: Understanding the intergenerational transmission of Human Capital, American Economic Review 95 (1): 437-449.

Brook, J., Whiteman, S. M. and Zheng, L. (2002). Intergenerational transmisson of risks for problem behavior- Statistical Data Included, Journal of Abnormal Child Psychology 30 (1): 65-76.

Burkhauser, R. and Cawley, J. (2008). Beyond BMI: The value of more accurate measures of fatness and obesity in social science research., Journal of Health Economics 27: 519-529.

Case, A., Fertig, A. and Paxson, C. (2005). The Lasting Impact of Childhood Health and Circumstance, Journal of Health Economics 24 (2): 365-389.

Case, A., Lubotsky, D. and Paxson, C. (2002). Economic Status and Health in Childhood: The Origins of the Gradient, American Economic Review 92 (5): 13081334 .

Case, A. and Paxson, C. (2001). Mothers and others: who invests in children's health?, Journal of Health Economics 20: 301-328.

Case, A. and Paxson, C. (2008). The income gradient in children's health: A comment on Currie, Shields and Wheatley Price., Journal of Health Economics 27 (3): 801-807.

Cawley, J. and Spiess, K. (2008). Obesity and Skill Attainment in Early Childhood, Economics and Human Biology (forthcoming). 
Collins, J. W., Wu, S. Y. and David, R. (2002). Differing Intergenerational Birth Weights Among the Descandants of U.S.- born and Foreign- born Whites and African Americans in Ilinois., American Journal of Epidemiology 155: 210-216.

Conley, D. and Bennett, N. (2000). Is Biology Destiny? Birth Weights and Life Chances., American Sociological Review 65: 458-467.

Coutinho, R., David, R. and Collins, J. (1997). Relation of Parental Birth Weights to Infant Birth Weight Among African Americans and Whites in Illinois., American Journal of Epidemilogy 146: 804-809.

Currie, J. and Hyerson, R. (1999). Is the Impact of Health Shocks Cushioned by Socioeconomic Status? The Case of Low Birth Weight, American Economic Review 89: 245-250.

Currie, J. and Moretti, E. (2005). Biology as Destiny? Short and Long-Run Determinants of Intergenerational Transmission of Birth Weight, NBER Working Paper No. 11567 .

Currie, J. and Neidell, M. (2005). Air pollution and Infant Health: What can we learn from California's Recent Expierence?, The Quarterly Journal of Economics 120 (3): 1003-1030.

Currie, J. and Stabile, M. (2006). Child Mental Health and Human Capital Accumulation: The Case of ADHD, Journal of Health Economics 25 (6): 1094-1118.

Currie, J. and Stable, M. (2003). Socioeconomic Status and Health: Why is the Relationship Stronger for Older Children, American Economic Review 93: 18131823.

Ding, W., Lehrer, S., Rosenquist, N. J. and J.McGovern-Audrain (2006). The Impact of Poor Health on Education: New Evidence Using Genetic Markers, NBER Working Paper No.12304.

Duncan, G. J., Claessens, A., Huston, A. C., Pagani, L. S., Engel, M., Sexton, H., Dowsett, C. J., Magnuson, K., Klebanov, P., Feinstein, L., Brooks-Gunn, J. and Duckworth, K. (2007). School Readiness and Later Achievement, Developmental Psychology 43 (6): 1428-1446.

Duncan, T. (1994). Like Father, Like Son: Like Mother, Like Daughter, Journal of Human Resources 29 (4): 950-988. 
Dunkelberg, A. and Spiess, C. K. (2008). The Impact of Child and Maternal Health Indicators on Female Labor Force Participation after Childbirth - Evidence for Germany, Journal of Compartative Family Studies, (forthcoming) .

Goode, A., Mavromaras, K. G. and Smith, M. (2008). Intergenerational Transmission of Healthy Eating Behaviour and The Role of Household Income, IZA Discussion Paper No. 3535 .

Goodman, E., Hinden, B. and Khandelwal, S. (2000). Accuracy of teen and parental reports of obesity and body mass index., Pediatrics 106: 52-58.

Heckman, J. J. (2007). The Economics, Technology and Neuroscience of Human Capability formation., PNAS 104 (33): 13250-13255.

IOTF (2004). EU Childhood obesity "out of control", IOTF Childhood Obesity Report May .

Kebede, B. (2003). Genetic Endowments, Parental and Child Health in Rural Ethopia., The Centre for the Study of African Economies Working Paper Series 193.

Kurth, B. M., Hölling, H. and Schlack, R. (2008). Die Verbreitung von Übergewicht und Adipositas bei Kinderns und Jugendlichen in Deutschland. Ergebnisse des bundesweiten Kinder- und Jugendgesundheitssurveys (KiGGS), in Mittelmass für Kinder. Der Unicef-Bericht zur Lage der Kinder in Deutschland, Betram, H.(ed.) pp. 104-126.

Kurth, B. M. and Schaffrath, A. R. (2007). Die Verbreitung von Übergewicht und Adipositas bei Kinderns und Jugendlichen in Deutschland. Ergebnisse des bundesweiten Kinder- und Jugendgesundheitssurveys (KiGGS), Bundesgesundheitsblatt- Gesundheitsforschung- Gesundheitsschutz. 50: 736-743.

Mahler, P. (2007). I'm not fat, just too short for my weight, Working Paper University of Zürich.

Marshall, T., Jones, D. P. H., Ramchandani, P. G., Stein, A. and Bass, C. (2007). Intergenerational transmisson of health beliefs in somatoform disorders, The British Journal of Psychiatry 191: 449-450.

Poskitt, E. (1995). Defining childhood obesity: the relative body mass index (BMI), Acta Pediatric 84: 961-963. 
Rimal, R. N. (2003). Intergenerational Transmission of Health: The Role of Intrapersonal, Interpersonal, and Communicative Factors, Health Education and Behavior 30 (1): 10-28.

Salm, M. and Schunk, D. (2008). The Role of Childhood Health for the Intergenerational Transmission of Human Capital: Evidence from Administrative Data, IZA Discussion Paper Bonn No. 3646.

Schwarze, J., Anderson, H. H. and Anger, S. (2000). Self-rated health and changes in self-rated health as predictors of mortality, DIW Discussion Paper No. 203, Berlin .

Singh-Manoux, A., Gueguen, A., Martikainen, P., Ferrie, J., Marmot, J. M. and Shipöey, M. (2007). Self-rated health and mortality: Short- and long-term associations in the Whitehall II Study, Psychosomatic Medicine 69: 138-143.

Thomas, D. (1994). Like Fahter, Like Son; Like Mother, Like Daughter, Journal of Human Resources 29: 950-988.

Wagner, G. G., Frick, J. and Schupp, J. (2007). Schmollers Jahrbuch .

Wickrama, K. A. S., Conger, R. D., Wallace, L. E. and G. H. Elder, J. (1999). Intergenerational Transmission of Health- Risk Behavior: Adolescent Lifestyles and Gender Moderating Effects, Journal of Health and Social Behavior 40 (3): 258272. 


\section{A Appendix}

Table A.1: Summary Statistics of children's and paternal health measures

\begin{tabular}{llcccc}
\hline \hline & \multicolumn{3}{c}{$3-18$ months olds } & \multicolumn{2}{c}{$26-42$ months olds } \\
& mean & std.dev. & mean & std.dev. \\
\hline \multirow{2}{*}{ Child's health } & & \\
Child's number of doctor visits within 3 months & 1.59 & $(3.04)$ & 1.44 & $(2.14)$ \\
Child's hospital visits & 1.43 & $(6.94)$ & 0.19 & $(2.24)$ \\
Worried about my child's health 'no' & 0.59 & $(0.49)$ & 0.58 & $(0.49)$ \\
Child's disorder & 0.08 & $(0.66)$ & 0.30 & $(0.46)$ \\
Child's BMI & 12.76 & $(1.84)$ & 16.03 & $(3.58)$ \\
Child obese & 0.05 & $(0.23)$ & 0.09 & $(0.28)$ \\
\hline & \multicolumn{2}{c}{ Mother's health } & & \\
Mother's current doctor visits & 4.37 & $(3.84)$ & 2.10 & $(3.28)$ \\
Mother's nights spent in hospital last year & 1.27 & $(3.96)$ & 1.00 & $(7.94)$ \\
Mother current health status 'very good' & 0.18 & $(0.38)$ & 0.13 & $(0.34)$ \\
Mother current health status 'good' & 0.53 & $(0.50)$ & 0.51 & $(0.50)$ \\
Mother current health status 'poor' & 0.21 & $(0.41)$ & 0.27 & $(0.44)$ \\
Current health status 'bad' & 0.06 & $(0.24)$ & 0.10 & $(0.31)$ \\
Smoking & 0.18 & $(0.38)$ & 0.22 & $(0.42)$ \\
BMI & 23.87 & $(4.14)$ & 24.38 & $(4.58)$ \\
Mother obese & 0.08 & $(0.27)$ & 0.11 & $(0.32)$ \\
\hline & \multicolumn{3}{c}{ Father's health } & & \\
Father's current doctor visits & 1.19 & $(2.10)$ & 1.09 & $(1.83)$ \\
Father's nights spend in hospital last year & 0.90 & $(6.63)$ & 0.36 & $(1.89)$ \\
Smoking & 0.34 & $(0.48)$ & 0.34 & $(0.47)$ \\
BMI & 25.41 & 3.49 & 23.20 & $(8.59)$ \\
Father obese & 0.09 & $(0.29)$ & 0.12 & $(0.32)$ \\
\hline \hline Data Sor & & &
\end{tabular}

Data Source: Sample drawn from the SOEP 2002-2006, $\mathrm{N}=568,376$. 
Table A.2: Summary Statistics of control variables

\begin{tabular}{lllll}
\hline \hline & \multicolumn{2}{c}{$3-18$ months olds } & \multicolumn{2}{c}{$26-42$ months olds } \\
& mean & std.dev. & mean & std.dev. \\
\hline Equivalence income in 1000 Euro (annual) & 35.83 & $(21.57)$ & 36.62 & 19.45 \\
Mother's occupational degree & 0.66 & $(0.47)$ & 0.69 & $(0.47)$ \\
Mother's university degree & 0.23 & $(0.42)$ & 0.20 & $(0.40)$ \\
Father's occupational degree & 0.64 & $(0.48)$ & 0.62 & $(0.49)$ \\
Father's university degree & 0.30 & $(0.46)$ & 0.25 & $(0.43)$ \\
Single parent household & 0.01 & $(0.11)$ & 0.08 & $(0.26)$ \\
Private health insurance & 0.25 & $(0.43)$ & 0.21 & $(0.41)$ \\
Migration & 0.12 & $(0.33)$ & 0.15 & $(0.36)$ \\
Municipality & 4.18 & $(1.85)$ & 4.11 & $(1.76)$ \\
Child's age (in months) & 8.0 & $(3.28)$ & 33.36 & $(4.0)$ \\
Mother's age at birth (in years) & 30.93 & $(5.29)$ & 30.24 & $(5.30)$ \\
Father's age at birth (in years) & 34.19 & $(5.85)$ & 30.28 & $(12.33)$ \\
Gender & 0.49 & $(0.50)$ & 0.51 & $(0.50)$ \\
Siblings (1= yes) & 0.56 & $(0.50)$ & 0.56 & $(0.50)$ \\
\hline \hline
\end{tabular}

Data Source: Sample drawn from the SOEP 2002-2006, $\mathrm{N}=568,376$.

\section{B Cross-section results}




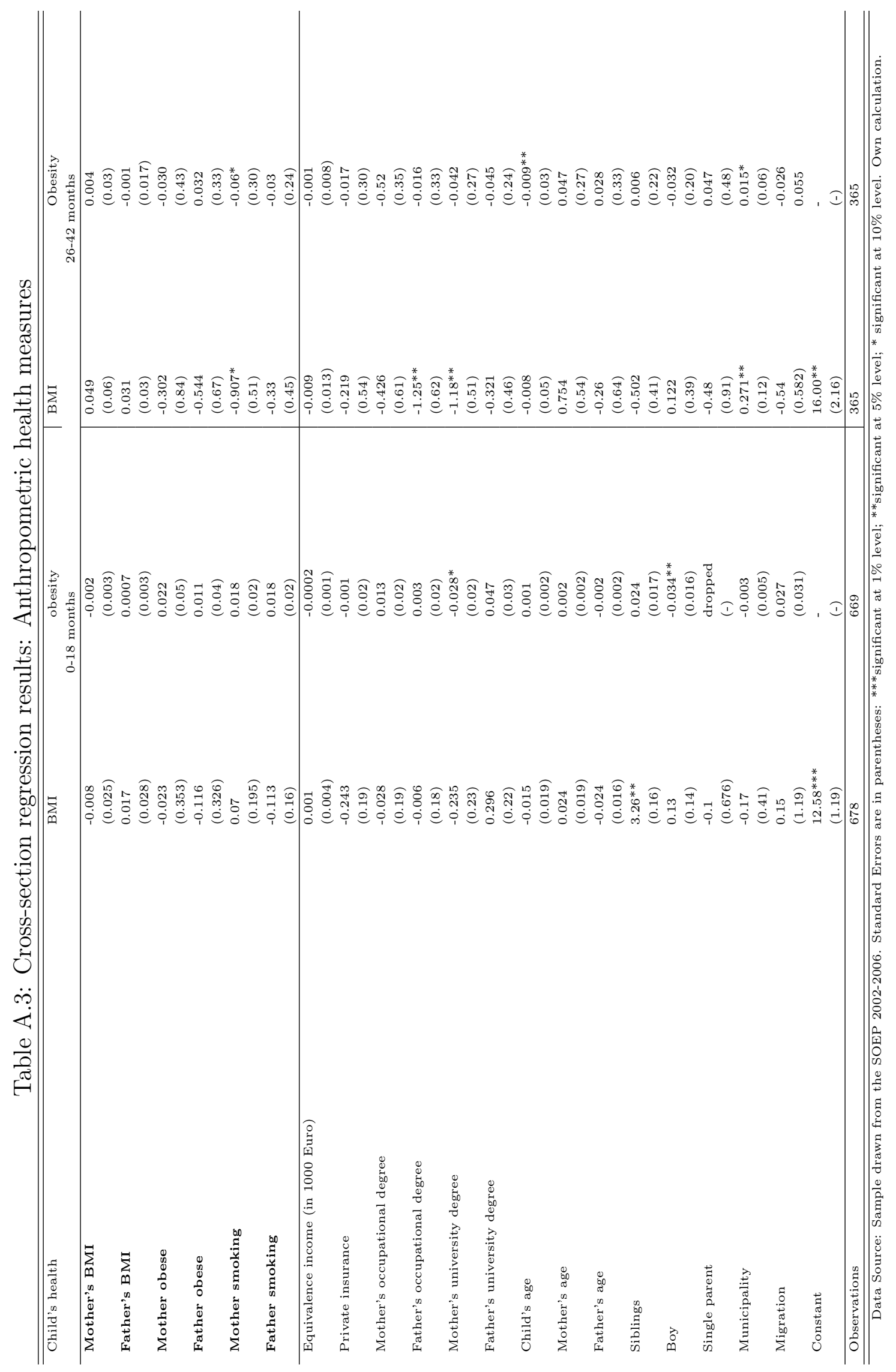




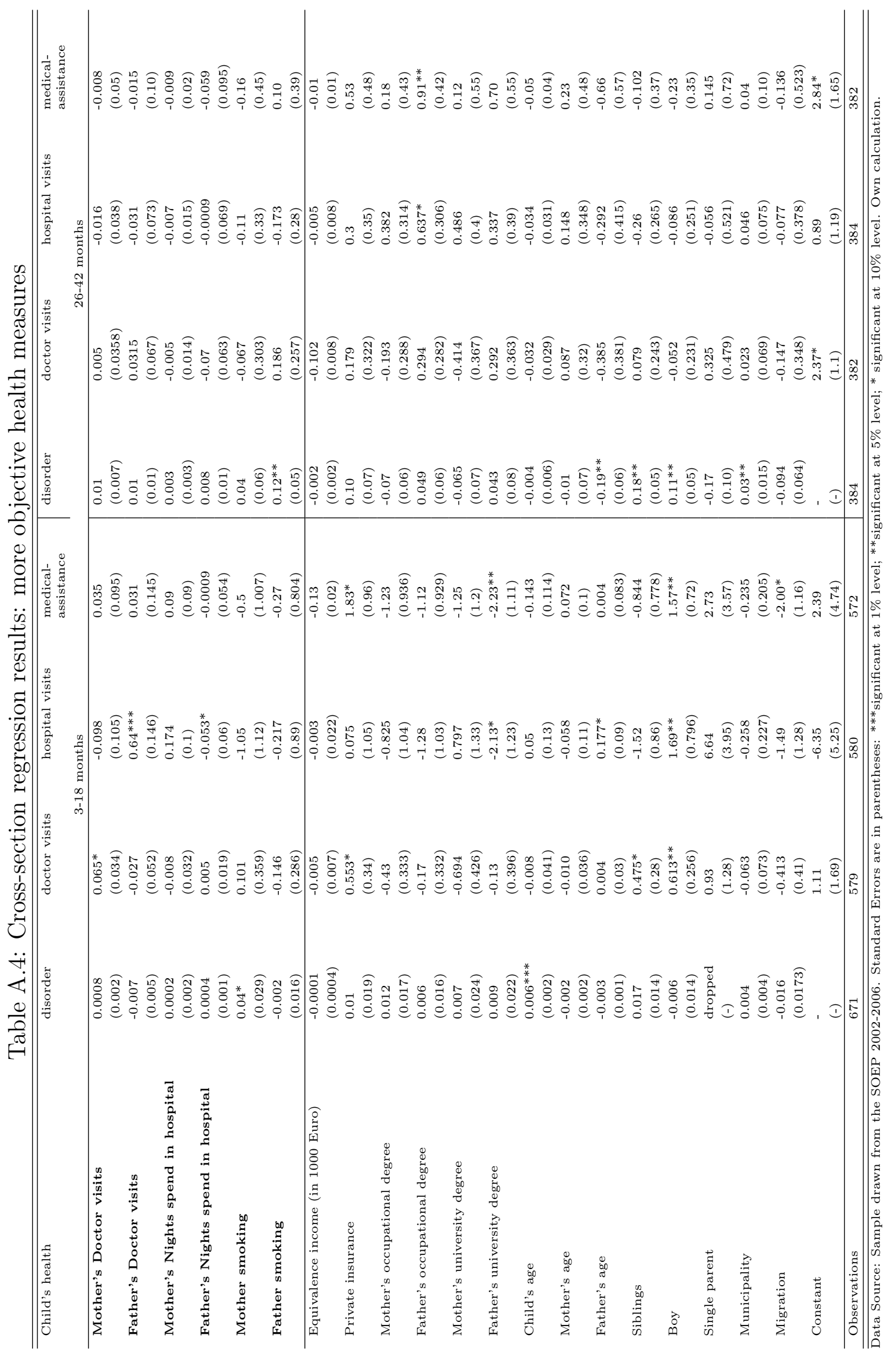




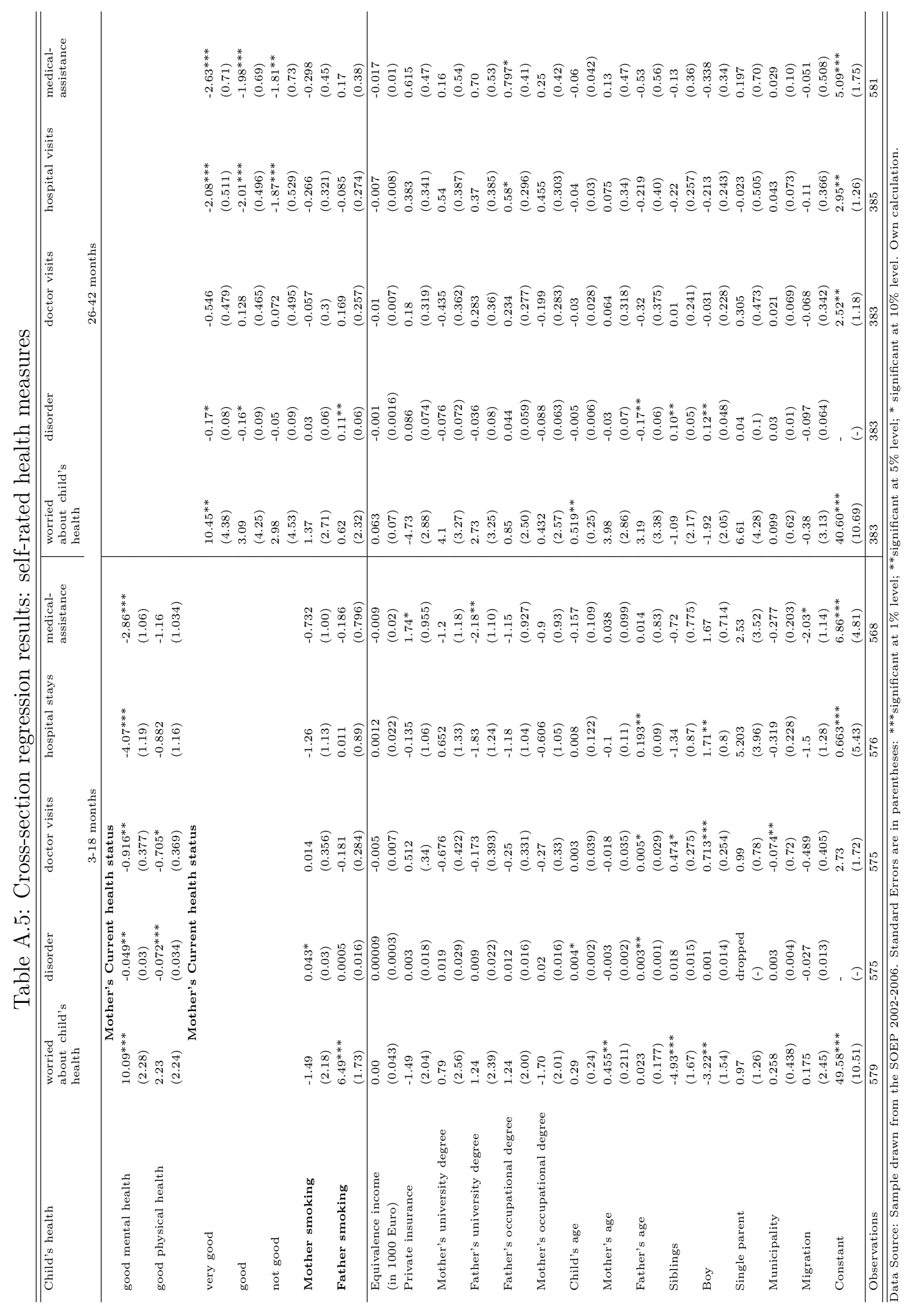




\section{Fixed Effect results}

Table A.6: Fixed Effects Results: Anthropometric measures

\begin{tabular}{|c|c|c|}
\hline Child's health & $\mathrm{BMI}$ & obesity \\
\hline \multirow[t]{2}{*}{ Mother's BMI } & -0.15 & -0.015 \\
\hline & $(0.14)$ & $(0.01)$ \\
\hline \multirow[t]{2}{*}{ Father's BMI } & $0.57^{* *}$ & 0.014 \\
\hline & $(0.359)$ & $(0.026)$ \\
\hline \multirow[t]{2}{*}{ Mother obese } & 1.24 & $0.26^{*}$ \\
\hline & $(1.33)$ & $(0.13)$ \\
\hline \multirow[t]{2}{*}{ Father obese } & -1.22 & 0.03 \\
\hline & $(1.06)$ & $(0.11)$ \\
\hline \multirow[t]{2}{*}{ Mother smoking } & 0.02 & -0.04 \\
\hline & $(1.01)$ & $(0.10)$ \\
\hline \multirow[t]{2}{*}{ Father smoking } & $-1.44^{*}$ & -0.02 \\
\hline & $(0.85)$ & $(0.09)$ \\
\hline \multirow[t]{2}{*}{ Equivalence income (in 1000 Euro) } & 0.009 & $0.004^{* *}$ \\
\hline & $(0.017)$ & $(0.002)$ \\
\hline \multirow{2}{*}{ Private insurance } & $-2.43^{* *}$ & 0.04 \\
\hline & $(1.25)$ & $(0.13)$ \\
\hline \multirow[t]{2}{*}{ Mother's occupational degree } & 0.58 & -0.29 \\
\hline & $(2.64)$ & $(0.27)$ \\
\hline \multirow[t]{2}{*}{ Father's occupational degree } & -1.33 & $-0.18^{*}$ \\
\hline & $(0.97)$ & $(0.10)$ \\
\hline \multirow[t]{2}{*}{ Mother's university degree } & 1.09 & 0.04 \\
\hline & $(4.54)$ & $(0.46)$ \\
\hline \multirow[t]{2}{*}{ Father's university degree } & -0.38 & -0.03 \\
\hline & $(2.73)$ & $(0.27)$ \\
\hline \multirow{2}{*}{ Child's age } & $0.13^{* * *}$ & 0.0015 \\
\hline & $(0.01)$ & $(0.0014)$ \\
\hline \multirow[t]{2}{*}{ Siblings } & -0.29 & -0.007 \\
\hline & $(0.40)$ & $(0.04)$ \\
\hline \multirow[t]{2}{*}{ Municipality } & $0.82^{* *}$ & 0.03 \\
\hline & $(0.34)$ & $(0.03)$ \\
\hline \multirow[t]{2}{*}{ Constant } & -0.59 & 0.16 \\
\hline & $(7.22)$ & $(0.73)$ \\
\hline Observations & 400 & 400 \\
\hline
\end{tabular}

Data Source: Sample drawn from the GSOEP 2002-2006. Standard Errors are in parentheses: ${ }^{* * *}$ significant at $1 \%$ level; ${ }^{* *}$ significant at $5 \%$ level; ${ }^{*}$ significant at $10 \%$ level. Own calculation. 
Table A.7: Fixed Effects Results: more objective health measures

\begin{tabular}{|c|c|c|c|c|}
\hline Child's health & disorder & doctor visits & $\begin{array}{l}\text { hospital } \\
\text { stays }\end{array}$ & $\begin{array}{l}\text { medical } \\
\text { assistance }\end{array}$ \\
\hline \multirow[t]{2}{*}{ Mother's Doctor visits } & -0.0005 & 0.001 & -0.05 & -0.06 \\
\hline & $(0.005)$ & $(0.04)$ & $(0.09)$ & $(0.11)$ \\
\hline \multirow[t]{2}{*}{ Father's Doctor visits } & -0.01 & -0.04 & 0.17 & 0.13 \\
\hline & $(0.01)$ & $(0.07)$ & $(0.18)$ & $(0.21)$ \\
\hline \multirow[t]{2}{*}{ Mother's Nights spend in hospital } & 0.004 & -0.04 & 0.02 & 0.001 \\
\hline & $(0.003)$ & $(0.04)$ & $(0.05)$ & $(0.11)$ \\
\hline \multirow[t]{2}{*}{ Father's Nights spend in hospital } & 0.007 & -0.024 & -0.23 & -0.25 \\
\hline & $(0.01)$ & $(0.07)$ & $(0.19)$ & $(0.22)$ \\
\hline \multirow[t]{2}{*}{ Mother smoking } & 0.16 & 0.16 & 0.30 & 0.27 \\
\hline & $(0.10$ & $(0.68)$ & $(1.78)$ & $(2.04)$ \\
\hline \multirow[t]{2}{*}{ Father smoking } & $0.16^{*}$ & 0.14 & $-3.23^{* *}$ & -3.06 \\
\hline & $(0.09)$ & $(0.65)$ & $(1.66)$ & $(1.90)$ \\
\hline \multirow[t]{2}{*}{ Equivalence income (in 1000 Euro) } & 0.0002 & 0.005 & -0.02 & -0.005 \\
\hline & $(0.002)$ & $(0.01)$ & $(0.03)$ & $(0.03)$ \\
\hline \multirow[t]{2}{*}{ Private insurance } & 0.05 & -0.30 & 0.58 & 0.21 \\
\hline & $(0.14)$ & $(0.96)$ & $(2.49)$ & $(2.86)$ \\
\hline \multirow[t]{2}{*}{ Mother's occupational degree } & -0.21 & -0.11 & -0.03 & -0.28 \\
\hline & $(0.26)$ & $(1.81)$ & $(4.55)$ & $(5.21)$ \\
\hline \multirow[t]{2}{*}{ Father's occupational degree } & 0.04 & 0.26 & 1.78 & 1.98 \\
\hline & $(0.11)$ & $(0.75)$ & $(1.85)$ & $(2.17)$ \\
\hline \multirow[t]{2}{*}{ Mother's university degree } & -0.29 & -0.26 & -0.57 & -1.21 \\
\hline & $(0.50)$ & $(3.49)$ & $(8.77)$ & $(10.05)$ \\
\hline \multirow[t]{2}{*}{ Father's university degree } & 0.30 & 2.28 & 4.50 & 6.75 \\
\hline & $(0.30)$ & $(2.10)$ & $(5.28)$ & $(6.05)$ \\
\hline \multirow[t]{2}{*}{ Child's age } & $0.008^{* * *}$ & -0.01 & $-0.07^{* * *}$ & $-0.09 * *$ \\
\hline & $(0.001)$ & $(0.01)$ & $(0.03)$ & $(0.03)$ \\
\hline \multirow[t]{2}{*}{ Siblings } & 0.04 & 0.21 & 0.98 & 1.34 \\
\hline & $(0.04)$ & $(0.29)$ & $(0.73)$ & $(0.85)$ \\
\hline \multirow[t]{2}{*}{ Municipality } & 0.03 & 0.005 & -0.23 & -0.24 \\
\hline & $(0.035)$ & $(0.24)$ & $(0.61)$ & $(0.70)$ \\
\hline \multirow[t]{2}{*}{ Constant } & -0.20 & 0.71 & 1.24 & 1.70 \\
\hline & $(0.27)$ & $(1.88)$ & $(4.73)$ & $(5.42)$ \\
\hline Observations & 409 & 409 & 409 & 409 \\
\hline
\end{tabular}

Data Source: Sample drawn from the SOEP 2002-2006. Standard Errors are in parentheses: *** significant at $1 \%$ level; ${ }^{* *}$ significant at $5 \%$ level; ${ }^{*}$ significant at $10 \%$ level. Own calculation. 
Table A.8: Fixed Effects Results: self-rated health measures

\begin{tabular}{|c|c|c|c|}
\hline Child's health & disorder & $\begin{array}{l}\text { worried about } \\
\text { child's health }\end{array}$ & $\begin{array}{l}\text { medical assis- } \\
\text { tance }\end{array}$ \\
\hline \multicolumn{4}{|l|}{ Mother's current health status } \\
\hline \multirow[t]{2}{*}{ very good } & $-0.27^{* * *}$ & $8.88^{* *}$ & -2.30 \\
\hline & $(0.09)$ & $(4.39)$ & $(1.91)$ \\
\hline \multirow[t]{2}{*}{ good } & $-0.26^{* * *}$ & 6.14 & -0.65 \\
\hline & $(0.08)$ & $(3.92)$ & $(1.72)$ \\
\hline \multirow[t]{2}{*}{ not good } & $-0.27^{* * *}$ & 5.27 & -0.72 \\
\hline & $(0.08)$ & $(3.87)$ & $(1.70)$ \\
\hline \multirow[t]{2}{*}{ Mother smoking } & 0.12 & 4.53 & 0.48 \\
\hline & $(0.10)$ & $(4.53)$ & $(2.02)$ \\
\hline \multirow[t]{2}{*}{ Father smoking } & $0.18^{* *}$ & -6.36 & -2.54 \\
\hline & $(0.09)$ & $(4.28)$ & $(1.86)$ \\
\hline \multirow[t]{2}{*}{ Equivalence income (in 1000 Euro) } & 0.0004 & -0.03 & -0.006 \\
\hline & $(0.002)$ & $(0.08)$ & $(0.03)$ \\
\hline \multirow[t]{2}{*}{ Private insurance } & 0.003 & -3.69 & 0.26 \\
\hline & $(0.14)$ & $(6.45)$ & $(2.87)$ \\
\hline \multirow[t]{2}{*}{ Mother's occupational degree } & -0.28 & 8.26 & 1.54 \\
\hline & $(0.24)$ & $(11.61)$ & $(4.97)$ \\
\hline \multirow[t]{2}{*}{ Father's occupational degree } & 0.05 & -1.12 & 1.58 \\
\hline & $(0.10)$ & $(4.87)$ & $(2.12)$ \\
\hline \multirow{2}{*}{ Mother's university degree } & -0.30 & 27.30 & -0.64 \\
\hline & $(0.49)$ & $(23.39)$ & $(10.0)$ \\
\hline \multirow[t]{2}{*}{ Father's university degree } & 0.28 & 16.35 & 6.01 \\
\hline & $(0.29)$ & $(13.95)$ & $(5.97)$ \\
\hline \multirow[t]{2}{*}{ Child's age } & $0.007^{* * *}$ & -0.02 & $-0.09^{* * *}$ \\
\hline & $(0.001)$ & $(0.06)$ & $(0.03)$ \\
\hline \multirow[t]{2}{*}{ Siblings } & 0.06 & 0.37 & $1.35^{*}$ \\
\hline & $(0.04)$ & $(1.94)$ & $(0.83)$ \\
\hline \multirow[t]{2}{*}{ Municipality } & 0.04 & -1.06 & -0.17 \\
\hline & $(0.03)$ & $(1.63)$ & $(0.70)$ \\
\hline \multirow[t]{2}{*}{ Constant } & 0.06 & $60.84^{* * *}$ & 0.97 \\
\hline & $(0.27)$ & $(12.61)$ & $(5.39)$ \\
\hline Observations & 409 & 408 & 409 \\
\hline
\end{tabular}

Data Source: Sample drawn from the SOEP 2002-2006. Standard Errors are in parentheses: ***significant at $1 \%$ level; ${ }^{* *}$ significant at $5 \%$ level; ${ }^{*}$ significant at $10 \%$ level. Own calculation. 